\title{
Surveying preschool teachers' use of digital tablets: general and technology education related findings
}

\author{
Anna Otterborn $^{1}$ (D) Konrad Schönborn ${ }^{2}$ (D) Magnus Hultén ${ }^{1}$ (D)
}

Accepted: 5 September 2018

(c) The Author(s) 2018

\begin{abstract}
The availability of digital tablets in preschools has increased significantly in recent years. Literature suggests that these tools can enhance students' literacy and collaborative skills. As society becomes increasingly digitized, preschool curriculum reform also emphasises the subjects of technology and science as priority areas of learning. Teachers' knowledge and experiences are of utmost importance in carrying out this mandate. Few studies have explored the use of digital tablets to teach preschool technology and science in Sweden, and there is an urgent need to ascertain the role of digital aids as teaching tools. This survey study seeks to determine how digital tablets are used to support preschool children's learning in general, and with respect to technology education. Preschool educators $(n=327)$ across Sweden responded to an online survey consisting of 20 closed and 6 open items that probed the use of digital tablets. Survey results revealed a high degree of engagement with digital tablets in preschools, with activities directed toward various subject-related, social and generic skills. Programming, invention, construction and creation, problem-solving, and design emerged saliently as tablet activities in technology subject areas. Opportunities for providing meaningful learning tasks and digital adaptability were seen as pedagogical benefits of using tablets, but increasing expectations to integrate tablet activities with an accompanying lack of digital skills were expressed as limitations. Teachers' recommendations for future tablet use included defining clearer curriculum guidelines for tablet implementation and adequate training for acquiring digital competence.
\end{abstract}

Keywords Digital tablets $\cdot$ Swedish preschool $\cdot$ Technology education $\cdot$ iPads

\section{Introduction}

The availability and use of digital tools such as tablet computers in early years education has increased significantly in recent years. Tablet computers (e.g. the Apple iPad) are rapidly emerging as a prominent feature of pedagogical practice at preschools, accepted

Anna Otterborn

anna.otterborn@liu.se

1 Department of Social and Welfare Studies (ISV), Linköping University, 60174 Norrköping, Sweden

2 Department of Science and Technology (ITN), Linköping University, 60174 Norrköping, Sweden 
and used by teachers and children alike. Through accessible digital resources such as tablets and the Internet, children interact with digital tools at an earlier age than ever before, quicker than before, and for increasing periods of their daily lives (e.g. Couse and Chen 2010). This marked trend calls for further development and reflection upon what dimensions constitute modern literacy practices in early years education contexts (Aldhafeeri et al. 2016; Bajovic 2018; Kjällander and Frankenberg 2018; Wohlwend 2015).

At the same time, recent literature stresses that educators need to take cognisance of children's digital competences and their ability to act independently in using digital tools. In this regard, Petersen (2015) suggests that at the preschool level, children's agency with digital tools - the active participation and independent activities of children based on their own choices and familiarity - needs to be carefully considered and integrated accordingly. It follows, that the rapid entry of new educational tools, such as digital tablets, into preschool environments places both novel and urgent demands on teachers to meaningfully support children's learning activities, while also satisfying curriculum mandates and expectations (Neumann and Neumann 2014; Strawhacker et al. 2017; Yelland and Masters 2007). As international curriculum proposals emerge, countries like Sweden are placing higher demands on the envisaged use of digital tools in general pre-school teaching activities and in subject-specific areas such as technology. This paper considers how digital tablets are used in general preschool teaching and specifically in technology education initiatives.

\section{Theoretical background}

\section{Integrating digital tools into technology education}

The integration of emerging digital tools in education has become a trending topic of debate over the last few decades (e.g. Neumann and Neumann 2014). Although there is a strong emphasis from government educational mandates to increase the use of digital tools in schools, much more empirical work is needed to investigate the influences and effects of integrating emerging digital resources as pedagogical tools in classroom practice (Luckin et al. 2012). For example, the assumption that the mere availability of digital tools transcends into meaningful learning outcomes is not simply a "given". One clear example is demonstrated by the PISA findings, where ICT use at school and at home has been shown to share a negative correlation with scores in science and mathematics (Spiezia 2011). In Sweden, a country that exhibits a high use of ICT-Swedish boys demonstrated the highest use of ICT among all PISA participants-such correlations have been flagged as a potential problem for learning (Swedish National Agency for Education 2015). One possible reason for increased ICT use being related to a decrease in science and mathematics achievement in various analyses, is the notion that since digital tools are "fragmented communicators", they could be associated with poorer reading literacy, as communicated by Rosén (2011). In fact, a longitudinal international analysis at the country level by Rosén and Gustafsson (2016) has revealed a negative relationship between ICT availability and reading achievement for Grade 4 pupils.

In terms of international research on the use of digital tablets in early years education, a review by Neumann and Neumann (2014) has provided evidence that the use of digital tablets was associated with improvements in children's verbal literacy skills. The review also pointed out that the type of scaffolding (e.g. reflective questions and positive 
feedback) employed by the teacher plays a large role in harnessing the potential advantages of tablets. Such findings call for more work on how tablet applications (apps) can be meaningfully integrated into formal curricula. Furthermore, in a study with 41 children in three northeastern United States preschool classrooms, Couse and Chen (2010) found that the manner in which teachers chose to integrate digital tablets had the most influence on children's learning. Overall, the research indicated that tablet computers provided teachers with an opportunity to implement learning objectives such as developing creative and innovative thinking, as well as demonstrating technology concepts and processes. In pursuing the learning of so-called "STEM" subjects, Aronin and Floyd (2013) have recommended that although children should be provided various opportunities to interact with tablets to develop digital competencies, only one app should be introduced at a time, in conjunction with focusing on a specific technology or science concept.

\section{Digital tablets in Swedish preschool teaching}

Recent national and international curriculum policies highlight notions such as developing pupils" "digital literacy" and taking cognisance of "literacies in the digital age" (see Lankshear and Knobel 2008, for a conceptual analysis). Indeed, living in an increasingly digitized society places complex demands on the formulation and adaptation of school curricula (Kress 1997). Sweden has recently engaged in overhauling national regulations concerning the use of digital tools in education, and a revised preschool curriculum with increased emphasis on digital literacy is expected in 2019. A proposal for a revised preschool curriculum was released in December 2017 (Swedish National Agency for Education 2017). In the proposal, digital tools are not explicitly linked to technology and science, but rather referred to in terms of a general aim to develop students' digital skills with respect to all curricular goals. This is in line with tensions between general and subject specific competencies observed in international policy movements (Nordin and Sundberg 2015). At the same time, and especially since 2010, the subject of technology has been given more emphasis in the preschool curriculum (Swedish National Agency for Education 2016a).

Overall, expected requirements are growing with respect to preschool teachers' use of digital tools in general (e.g. Lindahl and Folkesson 2012; Strawhacker et al. 2017), and in relation to the specific teaching of the technology subject (Aronin and Floyd 2013). However, a survey by the Swedish National Agency for Education (Skolverket) has revealed a clear disconnection between increased ICT availability and teachers' actual use of ICT in general classroom practice. Teachers in the survey also reported the urgent need for professional development in the use of ICT tools for teaching (Swedish National Agency for Education 2013). Moreover, apart from the apparent detachment between ICT availability and use, teaching science and technology has shown to be a significant challenge for preschool teachers, since they often lack sufficient content knowledge in these subjects (Hultén and Björkholm 2016).

The use of digital tablets in preschool education in Sweden is on the rise (e.g. Fridberg et al. 2017; Marklund 2015; Marklund and Dunkels 2016; Nilsen 2014; Palmér 2015; Petersen 2015). Research results are beginning to provide insight into the influence of different tablet-related activities in preschool pedagogical practice, and on prospective benefits and limitations. In terms of tablet activities, although preschool teachers are seen as an important component of engaging children in learning with digital tablets, research shows that teachers and children often have different aims (Nilsen 
2014). For example, Petersen (2015) has found that while a teacher's aims are often focused on the didactic features of a particular software application (app), a learner's focus might be on the aesthetic or entertainment features of the same resource. On this score, Palmér (2015) has shown that app design has a strong influence on the way preschool teachers choose to engage tablets in their participation with pupils during socially-mediated learning activities. Current work demonstrates that digital tablets afford a compelling multimodal communication that includes touch (the screen), portability, and various symbolic (e.g. pictorial and textual) display modes that can contribute to both independent and collaborative learning and teaching activities (Petersen 2015). In addition, both Marklund and Dunkels (2016) and Bajovic (2018) have provided fruitful directions for how tablets can be combined with play to enhance children's digital literacy and the learning of specific subject knowledge, while Fridberg et al. (2017) have shown how tablet activities can enhance children's reasoning about science concepts such as evaporation.

In contrast with documented pedagogical advantages, increasingly identified limitations of integrating tablets has been identified in a study by Marklund (2015) that analysed preschool teachers' online social network discussions around the use of tablets. The work found that teachers often discussed and raised the need for professional development and training in how to integrate tablets in actual pedagogical practice, and into the classroom environment. Consequently, in terms of recommendations for preschool implementation of tablets identified in the current literature, Marklund and Dunkels (2016) assert that preschool teachers need support in developing ways to reflect on their practice, while Palmér (2015) argues that teachers need to be provided with resources and guidance to design activities that strengthen the potential educational benefits of digital tablets.

Given the backdrop provided above, although empirical inquiry on the role of digital tablets as pedagogical tools is increasing in international contexts, Petersen (2015) has highlighted the fact that no survey has been carried out in Sweden that explores the prevalence and nature of digital tablet use in preschool. In addition, taking into account the impending Swedish preschool curriculum reform, very few studies have focused on uncovering how tablet computers are used in the teaching of technology.

\section{Aims of the study}

In line with the growing international literature on the role of digital tools in early years education, this survey study investigates the prevalence, features and aspects of digital tablet computers that teachers use in Swedish preschools-with a focus on technology. The study seeks to determine how digital tablets are used to support preschool children's learning in general, and with respect to technology related education. Specifically, the following research questions are posed:

- What educational activities with digital tablets do teachers engage in Swedish preschools?

- What are preschool teachers': 
- Views of the educational benefits and disadvantages of using digital tablets in teaching?

- Recommendations for using digital tablets in teaching practice?

\section{Method}

\section{Study context and survey design}

The study was conducted in Sweden with preschool teachers across the country being target respondents to an online survey. The survey was designed to generate information on teachers' use, experiences and opinions concerning digital tablets (e.g. iPads) in preschools, with an added focus on technology education.

Survey items included demographic information on gender, age, respondents' preschool location, level of education, number of available tablets, and teachers' own perceived level of competence in tablet use. An additional component of the questionnaire asked what programs or apps were used, how and why they were used during teaching activities, as well as teachers' opinions about the pedagogical advantages and disadvantages of using tablets in preschool education. A core aspect of the survey design was on uncovering the use of tablets in the teaching of technology. This included designing survey items that asked how often tablets were used in relation to technology content and what related activities were implemented in praxis. The items were designed iteratively over a period of 4 months and involved four cycles of revision and refinement during discussion between the authors. The design of the survey sought to strike a trade-off between specific and more general questions, followed by implementation of closed and open question item formats on a web-based survey platform (Andrews et al. 2007). The final step of survey development comprised piloting the electronic questionnaire with 16 preschool teachers in pursuit of face and content validity (e.g. Paneque and Barbetta 2006). Following subsequent incorporation of the teachers' suggested adjustments and clarifications, the final survey consisted of 26 items (20 closed and 6 open items).

\section{Data collection}

The survey was activated from November 2016 to April 2017. An invitation to participate in the survey together with an accompanying webpage link was emailed to 700 preschool directors across Sweden, who were requested to forward the survey link to preschool educators in their respective district. The survey invitation and link was also communicated on social media platforms that included multiple Facebook groups in Sweden such as, "iPads in schools and preschools" and Twitter. Aside from exposure on social media, and given that each preschool director is responsible for approximately 3 preschools with about 15 educators employed at each school, the estimated potential reach was in the order of 30,000 potential survey recipients. The first author monitored the breadth and nature of the responses as they were obtained, and it was deduced that 300 teacher responses would be an adequate sample size for pursuing a reliable analysis (e.g. Nunnally and Bernstein 1994). The data subjected to analysis comprised 327 individual survey activations, and serve as the response corpus analysed in this study. 


\section{Data analysis}

Apart from ascertaining the demographic characteristics and contexts of the survey respondents, this paper focuses on analysing responses to the following four open-ended survey items ${ }^{1}$ (numbered for cross-referencing purposes):

1. What programs and apps do you use in connection with the use of digital tablets in activities with the children? Please describe how you use this software and why you selected it.

2. Describe what you think is the biggest educational benefit of using digital tablets?

3. Describe what you think is the biggest educational disadvantage (if any) of using digital tablets in the activities with the children.

4. What recommendations do you have for further development of your digital tablet educational activities? Please give examples.

A qualitative thematic content analysis procedure was used to treat the response data (Mayring 2000). The process incorporated the following iterative steps, not always performed in a linear manner. Firstly, half of the responses were randomly selected and read by the first author on three separate occasions, while generating notes of any emerging interpretations of the data. Secondly, these impressions were used to inform a colour scheme to code the individual responses into inductively developed categories (Krippendorff 2004). Thirdly, in pursuit of agreement on the nature and meaning of emerging categories, the second and third authors performed their own independent category development on a smaller sample of responses (e.g. Goldring et al. 2009). Fourthly, after discussing the overall patterns and themes that emerged and subsequently reaching a consensus, the first author continued to analyse the main categories for any subcategory structure in the data (e.g. Corbin and Strauss 2008). Lastly, the main categories were described in terms of their respective incidence in the data, and also reflected upon in light of the Swedish preschool curriculum (Swedish National Agency for Education 2016a).

In addition to the thematic content analysis, Lundgren's (1981) frame factor theory was used as a lens to consider the implications of the categories for integrating digital tools in future technology related preschool education. Frame factor theory had its origin in Sweden in the 1960s where a suite of studies aimed to identify what particular factors were influencing observed educational outcomes. Lundgren's approach revealed that certain factors, later termed educational frames, inferred certain educational processes, which in turn, could be related to certain educational outcomes. Frames are defined as those influencing factors that are "determined outside the teaching process" (Lundgren 1981, p. 36). In this study, we adopt a frame factor approach to inform what frames may be perceived by preschool teachers in their pedagogical use of tablets. In doing so, the study draws on Imsen's (1999) model of five frames that influence educational practice to guide this reflection, namely, material (e.g. physical location, educational resources), normative (e.g. regulations, curriculum), social (e.g. teacher-children or children-children interactions, social climate), student related (e.g. learning prerequisites), and teacher related (e.g. teacher competence, teacher attitudes). Furthermore, the five frames can be associated with implications

\footnotetext{
1 Variations of the open-ended survey items included asking respondents to answer regardless of subject area as well as with respect to the specific subjects of technology and science.
} 
of educational practice on at least four different levels, namely, national level, local level, school level and classroom level. Overall, frame factor reflections could allow for the development of a broader understanding of what potential interventions may be required to improve practice with digital tablets in relation to technology education.

\section{Results}

Results of the study are structured as follows. First, the demographic features of the respondent sample, followed by emergent themes of preschool activities with digital tablets are presented. Second, examples of educational activities with digital tablets are described in light of the future Swedish preschool curriculum. Third, teachers' views of the educational advantages and disadvantages of using tablet computers in teaching are synthesised. Fourth, themes of teachers' recommendations for using tablets in preschool teaching practice are provided.

\section{Demographic characteristics and features of the survey respondents}

Demographics (gender, age and level of education) and context features (preschool location, pedagogical role and available number of tablets) of the respondent sample is summarised in Table 1.

The demographic data reveals that responses were obtained from across Sweden, with almost all of the respondents being female (Table 1). In addition, the survey revealed a distributed age of respondents, where the most common representative age was $41-50$ years (31.3\%). The most common level of education reported by respondents was post-secondary education longer than 3 years of tertiary education (66.8\%). Apart from the offered response alternatives, other pedagogical roles mentioned by $5.4 \%$ of respondents stated their pedagogical roles as including primary school, Montessori and/ or Reggio Emilia teachers. Lastly, $94.4 \%$ of respondents reported an availability of at least 1-4 digital tablets per preschool unit (Table 1).

\section{Emerging themes of digital tablet activities with children in preschool education}

Themes and categories that emerged from responses to survey item (1) (See "Method" section) and that capture preschool teachers' activities with digital tablets, are presented in Table 2 below.

Three overarching activity themes with tablets, comprising of eight main categories and six subcategories emerged from the analysis (Table 2). The subject-related theme of tablet activities comprised four categories, where much tablet activity was orientated towards language development (50\% of respondents) and the learning of technology and science (44\%). For the social skills-related theme (Table 2), 16\% of respondents contributed to the emergence a single category orientated toward cooperation and values in tablet activities. Three categories contributed to generic skills-related activities, with most $(54 \%)$ of the respondents describing documentation and reflection activities as most salient in their educational practice. 
A. Otterborn et al.

Table 1 Demographic characteristics and context features of survey respondents $(\mathrm{n}=327)$
Demographic and context features

Proportion of sample $(\%)^{*}$

\begin{tabular}{lr}
\hline Gender & \\
Female & 96.0 \\
Male & 3.4 \\
Other & 0.6 \\
Age & \\
$20-30$ & 16.4 \\
$31-40$ & 27.2 \\
$41-50$ & 31.3 \\
$51-60$ & 21.1 \\
$\geq 61$ & 4.0 \\
Pedagogical role & \\
Preschool teacher & 76.5 \\
Childminder & 18.1 \\
Other & 5.4 \\
Level of education & \\
Compulsory school & 4.7 \\
Gymnasium (upper secondary) & 19.3 \\
Post-secondary (3 years or less) & 21.4 \\
Post-secondary (>3 years) & 66.8 \\
Graduate studies & 1.2 \\
Preschool location in Sweden & \\
Northern Sweden & 13.0 \\
Central Sweden & 43.0 \\
Southern Sweden & 44.0 \\
Available digital tablets per preschool division** & \\
1-2 & 55.0 \\
3-4 & 39.4 \\
5 or more & 6.6 \\
\hline
\end{tabular}

*In some of the survey items more than one option could be selected

**A typical Swedish preschool contains approximately four divisions

\section{Emerging technology education activities with digital tablets in relation to the new preschool curriculum}

In addition to the overall themes of digital tablet activities presented in Table 2, analysis of the survey data revealed at least five emerging areas of tablet activities and accompanying apps or software programs concerned specifically with technology education content (Table 3).

Responses from the survey show that emerging tablet activities for teaching technology draw on aspects of programming, invention, construction and creation, problem-solving, as well as design (Table 3). At least eleven programs and apps were reported as being used in 


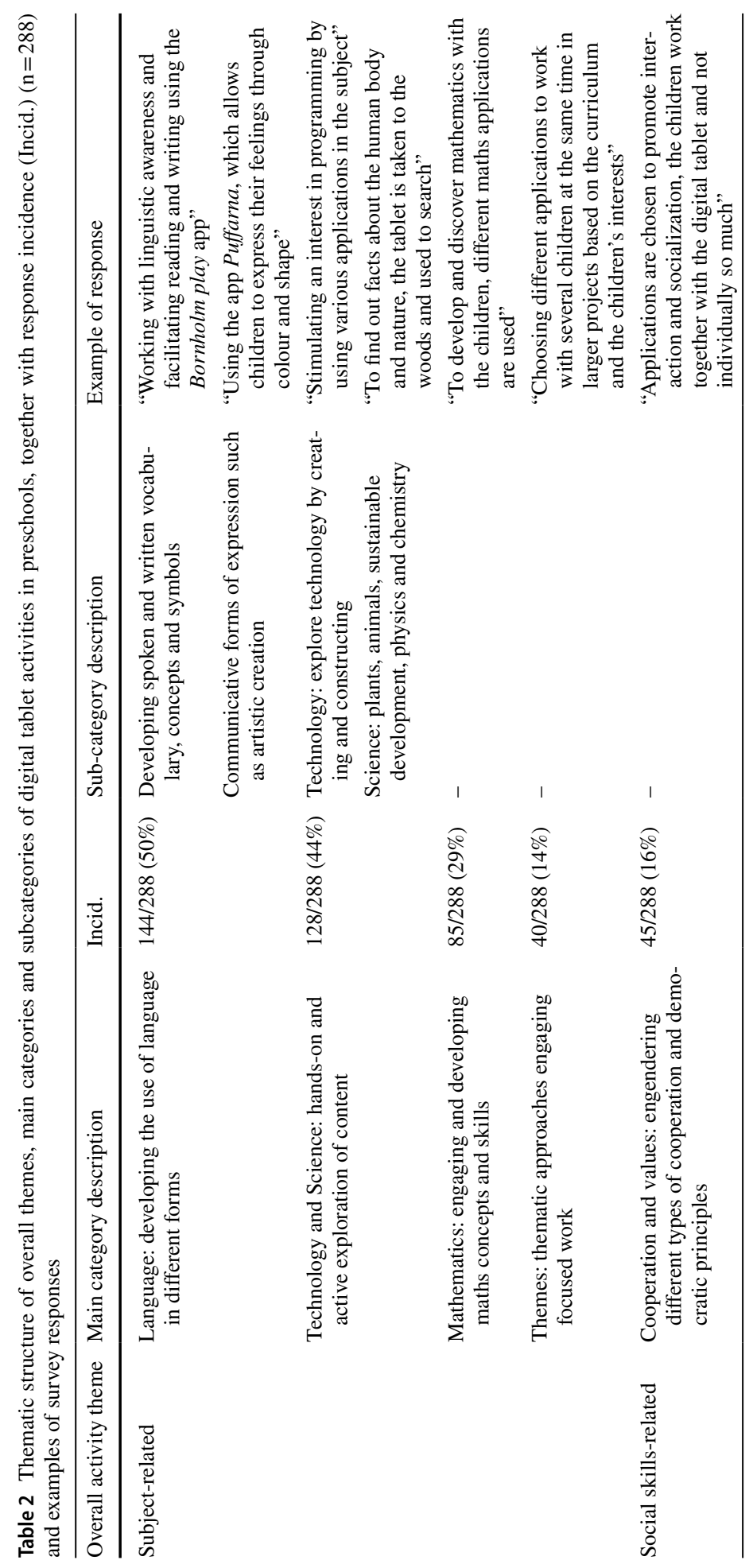




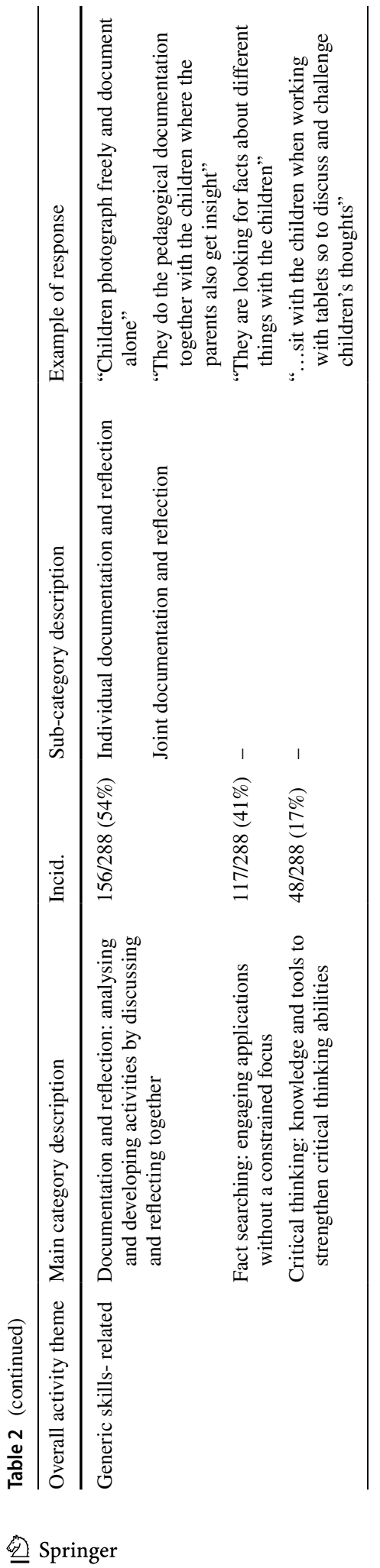




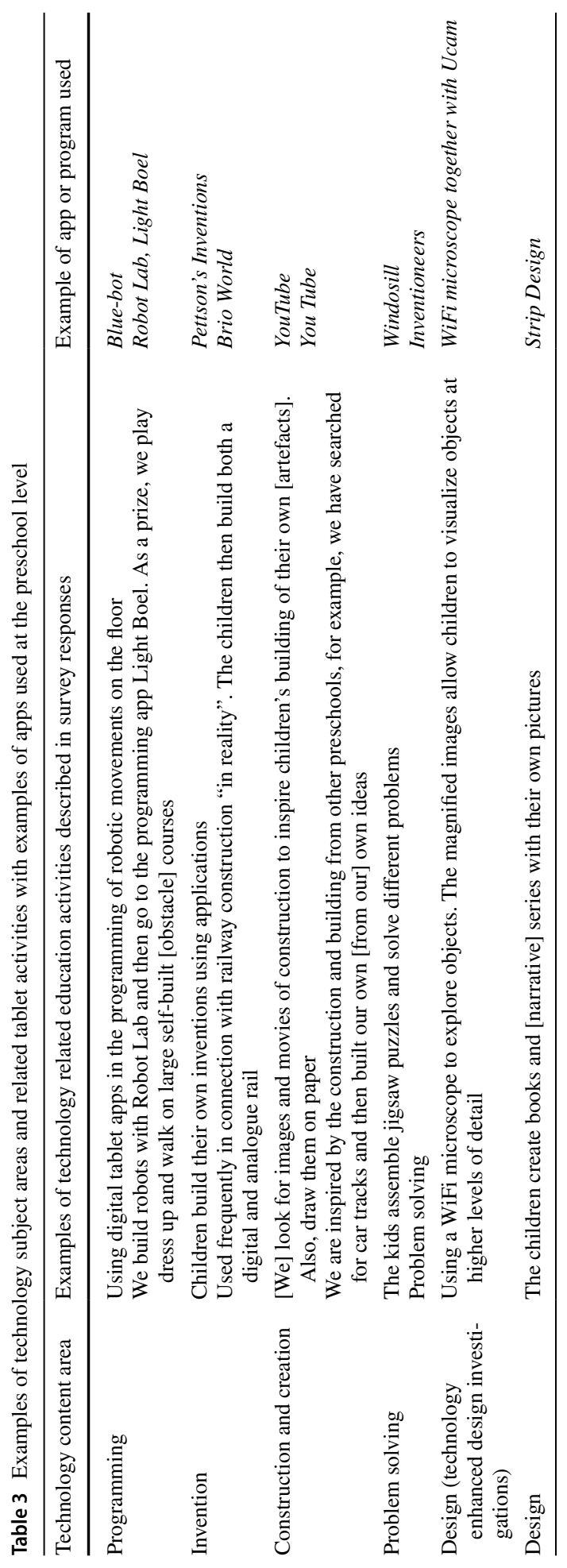




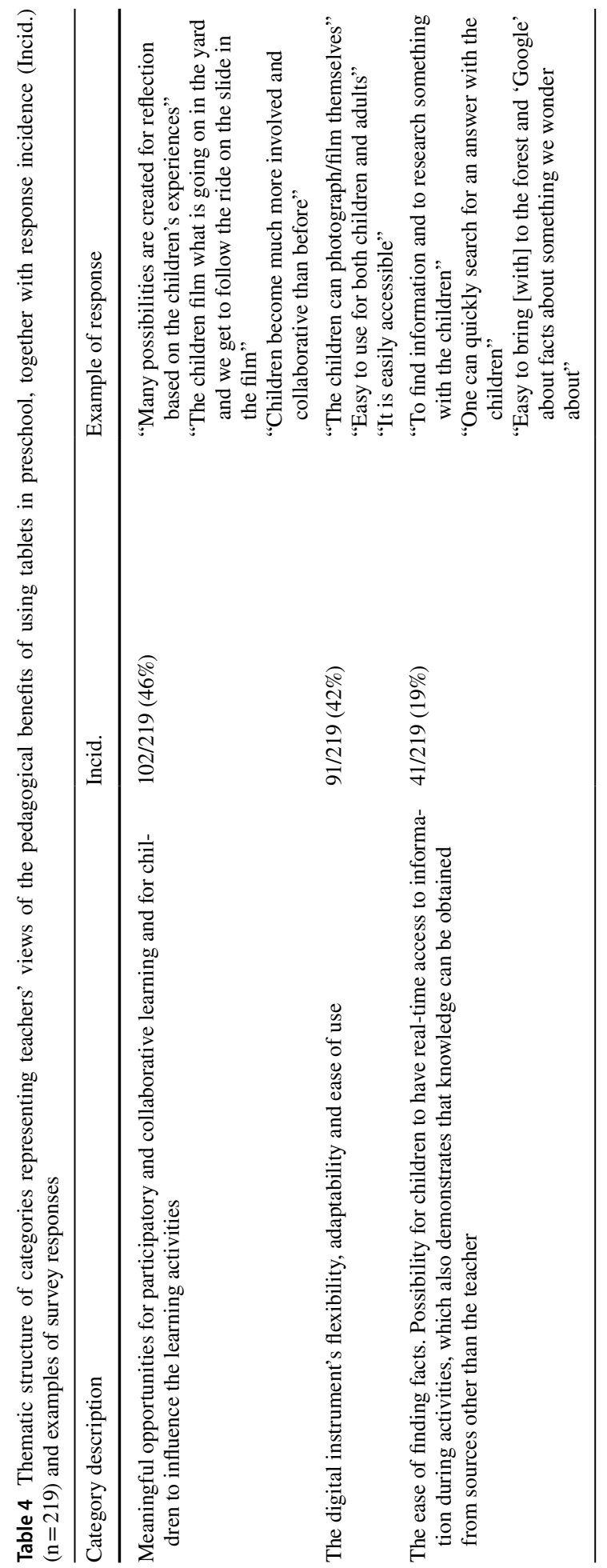


association with teachers' implementation of technology education related tablet activities. The activities are interconnected and also reflect the current Swedish preschool curriculum.

\section{Emerging themes of the advantages and limitations of using digital tablets in preschool education}

Results from analysis of teachers' responses to item (2) on their opinions about what they think are the greatest pedagogical benefits of using tablets in a preschool context are described in Table 4.

The survey revealed two salient categories of teachers' perceived benefits of using digital tablets (Table 4). One major category centred on the use of tablets in participatory and collaborative learning, where children have opportunities to reflect upon and influence the activities (46\%). The other prominent category of perceived advantage was on the flexibility of digital tablet technology and associated usability and adaptability for various activities (42\%). A fifth of the respondents also viewed the real-time information-gathering attribute of tablets as a useful pedagogical advantage.

In contrast with the emergent categories of teachers' views on the pedagogical advantages and merits of tablets, Table 5 communicates categories of teachers' opinions about the limitations and potential disadvantages of using tablets in preschools, obtained from analysis of responses to item (3).

Teachers in the survey exposed at least three evenly prevalent distinct categories of perceived limitations and disadvantages associated with the use of digital tablets in preschool education (Table 5). These focused on shortcomings in the resources available for the meaningful integration of tablet use (37\%), on the curricular goals and associated regulatory expectations on teachers to implement tablets in practice (30\%), and on a deficiency of necessary digital skills to successfully engage tablet activities during teaching (28\%). Apart from these three themes, thirty (14\%) of the respondents flagged the challenge of promoting learners' independent learning on one hand, while on the other hand having to manage children's strong preference for engaging digital tablet technology during school time.

\section{Emerging themes of preschool teachers' recommendations for using digital tablets in teaching praxis}

In addition to teachers' expressed advantages and disadvantages with digital tablets as educational tools, analysis of survey item (4) revealed a set of recommendations that teachers have put forward for the future development and integration of tablet activities in preschool (Table 6).

More than half $(56 \%)$ of the preschool teacher respondents exposed the lucid recommendation that much more clearer and more informative guidelines are required to adequately implement tablet technology in practice. In relation to this direction, $44 \%$ of teachers also call for more systematic and standardised cooperation and dialogue between school management and grass root classroom implementation of tablet technology. Furthermore, preschool teachers also seek specific training in acquiring necessary digital skills and knowledge (38\%), while at the same time, $15 \%$ of respondents also highlight the need for adequate resources to be able to successfully implement tablet activity mandates. As a final recommendation, about a quarter of respondents (24\%) 


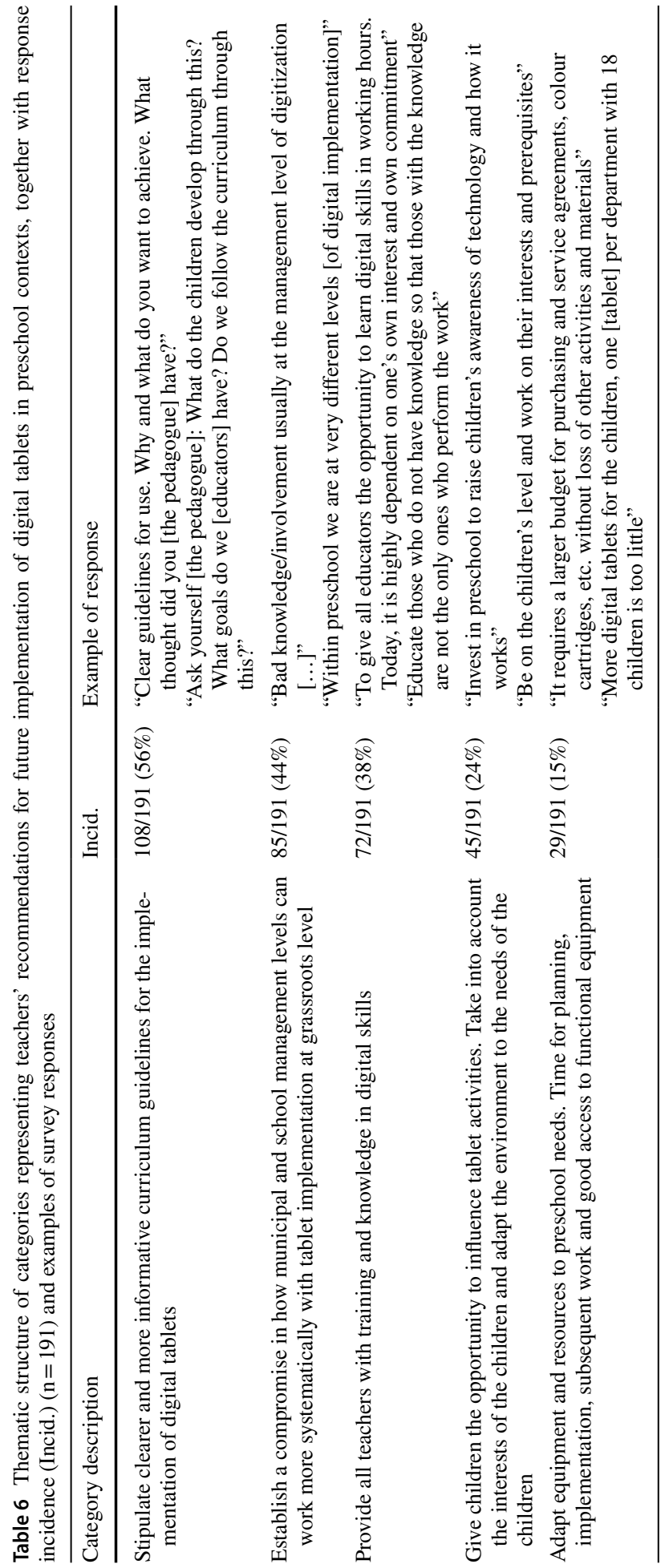


advocate that children's interests, awareness and views also be taken into account in future implementation of digital tablets.

\section{Discussion and implications}

The results of this study are discussed by revisiting the posed research questions, and in turn, raising potential implications for the use of digital tables in Swedish preschool technology education, and in general.

A total of 327 preschool teachers answered the questionnaire, although not all respondents completed all of the open questions, since they were not all obligatory. Some questions may also not have been deemed relevant for all respondents. For example, many respondents chose not to respond to the question probing their opinions about negative aspects of using digital tablets in preschool education. The geographical distribution of the survey was expansive, with answers spread across the three main regions of Sweden, which serves to provide a nationally representative indication of the current status of digital tablet integration in preschools. When considering the number of digital tablets per preschool unit, the sample demonstrates higher numbers than those acquired in a 2012 survey conducted by the Swedish National Agency for Education (2016b, p. 23). This might be an expected increase given that the iPad digital tablet was introduced for the first time in the Swedish market in 2011. In addition, many preschools only began to gain access to computer tablets in 2012 and 2013. However, given that a typical preschool incorporates approximately four divisions, our study shows that $55 \%$ of respondents only have access to 1-2 tablets per division (Table 1). The majority of the respondents were between 41 and 50 years of age, and the number of preschool teachers who responded to the survey was $76.5 \%$ (Table 1). Although they account for $39 \%$ of the preschool educator workforce in the Swedish preschool system (Swedish National Agency for Education 2016a, b), qualified preschool teachers were the most prevalent survey respondents.

\section{What educational activities with digital tablets do teachers engage in Swedish preschools?}

The survey results show that there is a great deal of engagement and interest in digital tablets among preschool teachers in Sweden that is encompassed in the use of various educational apps and internet-based resources. The different areas of knowledge covered include language, technology, science, and mathematics, which correspond to those specified in the curriculum, along with the aim to foster social and generic skills. All in all, the revealed activities reflect the majority of the curriculum goals, thus demonstrating that teachers have started to actively integrate digital tools in praxis. This finding bodes well for the vision of how digital tools are positioned in the proposed new curriculum, i.e. not as entities connected to certain content areas, but rather as more generic tools for learning (Swedish National Agency for Education 2017). Nevertheless, this position also raises questions and concerns around the balance between generic and subject specific skills.

Clearly, areas such as the generic skills of critical thinking and fact searching are pronounced. For example, critical thinking is not explicitly mentioned in the current curriculum, but is found in the proposal in conjunction with digital tools, indicating that fostering critical thinking is something that preschools already integrate. This also indicates that 
critical thinking and the use of digital tools may be seen to go hand in hand. According to Nilsen (2014), children's critical thinking can be greatly developed by interacting with digital tools in combination with teacher support. With regard to fact searching, we believe that although fact searching activities have existed long before digital tools, our results suggest that the prevalence of these activities indicate a possible relationship with the use of digital interfaces.

Programming activities also emerged saliently from the results. Although programming is not explicitly mentioned in the proposal for a new preschool curriculum, it was previously implemented in the revised elementary school curriculum (Swedish National Agency for Education 2011). This observation suggests that preschool may have gained inspiration from elementary school activities such as programming. In addition, the increased availability of applications in programming reveals programming competence to be increasingly emphasised at preschool level. This finding suggests that the use of digital tools is not only linked to traditional preschool activities, but might also be paving the way for learning new subjects and skills. Indeed, in the new Swedish elementary curriculum, programming is viewed as part of both technology and mathematics.

The prevalence of programming and critical thinking in our results point to the fact that many preschool teachers are eager to develop the use of digital tablets, and often take implementation steps prior to decision-making directives in pre-school activities (Nilsen 2014). In addition, even though critical thinking and fact searching certainly exist in more traditional (non-digital) practices in preschool to some extent, digital tools might offer alternative pedagogical pathways for meeting course goals. Finally, even though we see many areas of the curriculum being represented in the responses, the study does not illuminate upon how digital tools are actually integrated in day-to-day preschool educational practice. Hence, more work is required to ascertain whether digital activities occur disjointedly, or are progressively integrated with "non-digital" activities in a meaningful way.

\section{What are preschool teachers' views of the educational benefits and disadvantages of using digital tablets in teaching?}

The analysis of responses to this question are represented in Tables 4 and 5. The advantages generated three themes while the disadvantages generated four themes. Regarding the advantages, the first theme touched on how digital tablets allow children to become more involved in educational activities, and also influence them, while the other two themes concerned digital tablets as an educational tool that is adaptable and provides swift access to information (Couse and Chen 2010; Nilsen 2014; Petersen 2015). All three themes deal with general aspects of educational activities, and do not yield subject specific issues in relation to particular subject areas.

In terms of the revealed disadvantages, three categories were related to a lack of resources (time, equipment and staff) and a lack of competence (Bers et al. 2013; Hultén and Björkholm 2016; Petersen 2015). However, the fourth category around challenges in handling children's influence in working with digital tablets shows another interesting influential perspective of what the teachers saw as advantageous. Thus, children's influence seems to be viewed as both a positive as well as a challenging aspect in the use of digital tablets (Yelland and Masters 2007). The challenging aspect seems to be around solving questions such as for what duration children should be permitted to engage with tablets, and what applications children should have access to during these times. The positive aspect concerns the increased possibilities the use of digital tablets provides in terms 
of children's own influence of the actual pedagogical task and outcome. Further research is needed to understand what may lie behind these observations. In this regard, it is important to consider what is already being done in preschools, as this study reveals that many intriguing ideas and solutions are certainly being developed and integrated by preschool teachers at present.

\section{What are preschool teachers' recommendations for using digital tablets in teaching practice?}

The responses on recommendations for digital tablet use generated five themes. Overall, the themes asserted the following recommendations. Firstly, clearer and more informative curriculum guidelines for implementation of tablet technology are required. Secondly, more systematic and standardised cooperation and dialogue between school management and grass root classroom implementation must occur. Thirdly, there is a need for improving ICT competence, as was also highlighted in the revealed disadvantages of tablet integration (Hasse 2017; Håkansson and Lindqvist 2015). Fourthly, there is a need to raise children's own perspectives on tablet use, a theme that was also revealed in both the surveyed advantages and disadvantages of tablet technology. This finding stresses the importance of finding ways to best use digital tools in educational activities for increasing children's ability to influence learning, and taking account of their interests and needs, including emancipatory perspectives for providing children access to digital resources (Couse and Chen 2010; Falloon 2014; Hasse 2017; Nilsen 2014). The final recommendation concerned the resource perspective, which also emerged as being related to perceived disadvantages of digital tablets. Here, respondents highlighted the need for adequate resources, such as time for planning, implementation, subsequent work and suitable access to functional equipment as a prerequisite for successfully implementing tablet activity mandates. In spite of this, the proposed new preschool curriculum released in December 2017 (more than half a year after the current survey), indicates a notion that such guidelines may not be as informative and clear as hoped for. This perhaps comes as no surprise since the call for "clear guidelines" seems to be a recurrent reaction to every newly implemented curriculum since the late 1980s (at least in Sweden) (Lundahl 2009). Accordingly, clearer guidelines will have to be developed by other bodies in the educational system, such as by school management, through further training, or by preschool teachers themselves.

In conclusion, this survey study indicates that many Swedish preschools seem well prepared for the new demands related to digital tools that will come into force with the new preschool curriculum. As we look towards the future, it will be crucial to consider in what ways digital tools may influence technology teaching practices in pre-school. In a Swedish context, Imsen's (1999) frame factor theory offers a lens through which to contemplate the challenges and possibilities related to teachers' use of digital tools in preschool, and the extent to which technology education can be strengthened.

Imsen (1999) identifies five frames that affect educational practices: material (such as localities, educational technologies and materials), normative (such as regulations and the curriculum), social (interaction between teacher and children, between children, and social climate), student related (prerequisites for learning) and teacher related (teacher competence, attitudes, and subject knowledge.). These factors can be related to a social analysis on four different levels: a national/macro level, a local environment level, a school level and lastly, the classroom level (Imsen 1999). 
Not surprisingly, we find material and teacher related frames being saliently exposed by the preschool teachers in our study, which is linked to the supply of digital tools and how to use them. Regarding material frames, these seem to have been a concern for a long time. In the future, this frame is likely to be about stimulating a transformation from the mere prevalence of digital tablets towards more qualitative aspects such as programs/apps and technological support/infrastructure. Such issues have also being exposed by the teachers in our study. This frame might reflect large local discrepancies, which is also indicated in our results. The teacher related frames concerned lack of digital skills and knowledge about how to use digital tablets.

Regarding social frames, the example teacher statement that children "get crazy" (see Table 5) and all want to interact with the tablet, together with teachers mentioning the addictive nature of digital tools, indicate that social frames are present in working with tablets. However, overall, it seems that teachers suggest that digital tools facilitate social interaction between teachers and children or between children. Teachers' positive views on how digital tablets facilitate social interaction is also reflected by the fact that no studentrelated frames were mentioned, i.e. the teachers did not mention any obstacles regarding student prerequisites for learning.

In relation to digital tools, the above four frame factors may of course affect preschool technology education in various ways. Even more compelling in relation to the subject of technology are the results concerning the normative frame. The study shows that teachers seek more specific and pragmatic regulations. As already noted, we probably cannot expect clearer guidelines from the national curriculum level, which means that these guidelines have to be developed at other levels, such as at the local, school or classroom level. In turn, unpacking the "what" and "how" to teach with digital tools is not likely to become more regulated. Teachers will have to continue mostly as they do today, which implicates the content aspects of the normative frame. As shown in our study, many content areas are covered by the examples the teachers listed, which are both subject specific and more generic in nature. In this regard, researchers have noted an increased tension between development of subject specific and more generic competencies in policy documents (Nordin and Sundberg 2015). Such strains are also found in the proposal for a new preschool curriculum as mentioned earlier, and also in the emphasis on generic and social skills (see Table 2). However, based on the various examples of technology activities provided by the teachers in our study (programming, invention, construction and creation, problem-solving, and design), this seems largely unproblematic. It appears that tablets may in fact facilitate activities related to technology education, and that digital competence is a well-integrated component of learning technology. Even so, how exactly these efforts shall emphasise or influence different areas of technology education in the taught preschool curriculum requires further attention.

Open Access This article is distributed under the terms of the Creative Commons Attribution 4.0 International License (http://creativecommons.org/licenses/by/4.0/), which permits unrestricted use, distribution, and reproduction in any medium, provided you give appropriate credit to the original author(s) and the source, provide a link to the Creative Commons license, and indicate if changes were made.

\section{References}

Aldhafeeri, F., Palaiologou, I., \& Folorunsho, A. (2016). Integration of digital technologies into play-based pedagogy in Kuwaiti early childhood education: teachers' views, attitudes and aptitudes. International Journal of Early Years Education, 24(3), 342-360. 
Andrews, D., Nonnecke, B., \& Preece, J. (2007). Conducting research on the internet: Online survey design, development and implementation guidelines. International Journal of Human-Computer Interaction, 16(2), 185-210.

Aronin, S., \& Floyd, K. K. (2013). Using an iPad in inclusive preschool classrooms to introduce STEM Concepts. Teaching Exceptional Children, 45(4), 34-39.

Bajovic, M. (2018). Playing and learning across the concrete and digital realms: a new context for the new learners. International Journal of Play, 7(2), 199-209.

Bers, M. U., Seddighin, S., \& Sullivan, A. (2013). Ready for robotics: Bringing together the T and E of STEM in early childhood teacher education. Journal of Technology and Teacher Education, 21(3), 355.

Corbin, J. M., \& Strauss, A. L. (2008). Basics of qualitative research: Techniques and procedures for developing grounded theory (3rd ed.). Thousand Oaks: Sage.

Couse, L. J., \& Chen, D. W. (2010). A tablet computer for young children? Exploring its viability for early childhood education. Journal of Research on Technology in Education, 43(1), 75-98.

Falloon, G. (2014). What's going on behind the screens? Researching young students' learning pathways using iPads. Journal of Computer Assisted learning, 30(4), 318-336.

Fridberg, M., Thulin, S., \& Redfors, A. (2017). Preschool children's collaborative science learning scaffolded by tablets. Research in Science Education. https://doi.org/10.1007/s11165-016-9596-9.

Goldring, E., Huff, J., Spillane, J. P., \& Barnes, C. (2009). Measuring the learning-centered leadership expertise of school principals. Leadership and Policy in Schools, 8(2), 197-228.

Håkansson, \& Lindqvist, M. (2015). Exploring activities regarding technology enhanced learning in a one-to-one initiative. Nordic Journal of Digital Literacy, 10(4), 227-245.

Hasse, C. (2017). Technological literacy for teachers. Oxford Review of Education, 43(3), 365-378.

Hultén, M., \& Björkholm, E. (2016). Epistemic habits: Primary school teacher's development of pedagogical content knowledge (PCK) in a design-based research project. International Journal of Technology and Design Education, 26(3), 335-351.

Imsen, G. (1999). Reflection as a bridging concept between normative and descriptive approaches to didactics. In B. Hudson, F. Buchberger, P. Kansanen, \& H. Seel (Eds.), Didaktik/fachdidaktik as science $(-s)$ of the teaching profession? (pp. 95-105). Umeå: Umeå University, Department of Teacher Education and Research.

Kjällander, S., \& Frankenberg, S. (2018). How to design a digital individual learning RCT-study in the context of the Swedish preschool: Experiences from a pilot-study. International Journal of Research and Method in Education. https://doi.org/10.1080/1743727X.2018.1470161.

Kress, G. R. (1997). Before writing: rethinking the paths to literacy. London: Routledge.

Krippendorff, K. (2004). Content analysis: An introduction to its methodology (2nd ed.). Thousand Oaks, CA: Sage.

Lankshear, C., \& Knobel, M. (Eds.). (2008). Digital literacies: Concepts, policies and practices. New York: Peter Lang.

Lindahl, M. G., \& Folkesson, A. M. (2012). Can we let computers change practice? Educators' interpretations of preschool tradition. Computers in Human Behavior, 28(5), 1728-1737.

Luckin, R., Bligh, B., Manches, A., Ainsworth, S., Crook, C., \& Noss, R. (2012). Decoding learning: the proof, promise and potential of digital education. London: Nesta.

Lundahl, C. (2009). Varför nationella prov? Framväxt, dilemman, möjligheter. Lund: Studentlitteratur.

Lundgren, U. P. (1981). Model analysis of pedagogical processes. Lund: Liber.

Marklund, L. (2015). Preschool teachers' informal online professional development in relation to educational use of tablets in Swedish preschools. Professional Development in Education, 41(2), 236-253.

Marklund, L., \& Dunkels, E. (2016). Digital play as a means to develop children's literacy and power in the Swedish preschool. Early Years, 36(3), 289-304.

Mayring, P. (2000). Qualitative inhaltsanalyse: Grundlagen und techniken (7th ed.). Weinheim: Deutscher Studien Verlag.

Neumann, M. M., \& Neumann, D. L. (2014). Touch screen tablets and emergent literacy. Early Childhood Education Journal, 42(4), 231-239.

Nilsen, M. (2014). Barns aktiviteter med datorplattor I förskolan (Licentiate thesis, Nationella forskarskolan för ämnesdidaktik i Mångfaldens förskola. Förutsättningar och möjligheter för barns språkliga och matematiska utveckling och lärande (FoBaSM), nr 3). Available: http://hdl.handle.net/2077/37236.

Nordin, A., \& Sundberg, D. (2015). Introduction: The making and governing of knowledge in the education policy field. In A. Nordin \& D. Sundberg (Eds.), Transnational policy flows in European education: The making and governing of knowledge in the education policy field (pp. 9-20). Oxford: Symposium Books. 
Nunnally, J. C., \& Bernstein, I. H. (1994). Psychometric theory (3rd ed.). New York: McGraw-Hill.

Palmér, H. (2015). Using tablet computers in preschool: How does the design of applications influence participation, interaction and dialogues? International Journal of Early Years Education, 23(4), 365-381.

Paneque, O. M., \& Barbetta, P. M. (2006). A study of teacher efficacy of special education teachers of English language learners with disabilities. Bilingual Research Journal, 30(1), 171-193.

Petersen, P. (2015). That's how much I can do!: Children's agency in digital tablet activities in a Swedish preschool environment. Nordic Journal of Digital Literacy, 10(3), 145-169.

Rosén, M. (2011, 24 november). Datorer får barn att läsa mindre [Video file]. Retrieved from https:// www.youtube.com/watch? $\mathrm{v}=\mathrm{xkVcn} 0 \mathrm{ZmpMg}$.

Rosén, M., \& Gustafsson, J. (2016). Is computer availability at home causally related to reading achievement in grade 4? A longitudinal difference in differences approach to IEA data from 1991 to 2006. Large-scale Assessments in Education, 4(5), 1-19.

Spiezia, V. (2011). Does computer use increase educational achievements? Student-level evidence from PISA. OECD Journal: Economic Studies, 7(1), 1-22.

Strawhacker, A., Lee, M., \& Bers, M. (2017). Teaching tools, teachers' rules: exploring the impact of teaching styles on young children's programming knowledge in ScratchJr. International Journal of Technology and Design Education. https://doi.org/10.1007/s10798-017-9400-9.

Swedish National Agency for Education (2011). Läroplan för förskolan Lpfö 98. (2., rev. uppl.) Stockholm: Skolverket.

Swedish National Agency for Education. (2013). It-användning och it-kompetens i skolan. Rapport nr: 386. Stockholm: Fritzes.

Swedish National Agency for Education. (2015). It-användning och elevresultat i PISA 2012. Fokus på, 2015(3), 1-4.

Swedish National Agency for Education (2016a). Läroplan för förskolan Lpfö 98. ([Ny, rev. uppl.],]). Stockholm: Skolverket.

Swedish National Agency for Education. (2016b). IT-användning och IT-kompetens i skola (Utvärderingsavdelningen). Stockholm: Skolverket.

Swedish National Agency for Education. (2017). Förslag till reviderad läroplan för förskolan [Proposal for a revised preschool curriculum]. Dnr 2017:783. Retrieved from https://www.skolverket.se/polop oly_fs/1.266112!/Remiss_Laroplan_for_forskolan.pdf. 21 Dec 2017.

Wohlwend, K. E. (2015). One screen, many fingers: Young children's collaborative literacy play with digital puppetry apps and touchscreen technologies. Theory into Practice, 54(2), 154-162.

Yelland, N., \& Masters, J. (2007). Rethinking scaffolding in the information age. Computers \& Education, 48(3), 362-382. 